\title{
Statewide Costs of Healthcare-Associated Infections: Estimates for Acute Care Hospitals in North Carolina
}

\author{
Deverick J. Anderson, MD, MPH ${ }^{1}$, Deborah G. Pyatt ${ }^{2}$, David J. Weber, MD, MPH ${ }^{2,3}$, William \\ A. Rutala, PhD, MPH ${ }^{2,3}$, and North Carolina Department of Public Health HAl Advisory \\ Group \\ ${ }^{1}$ Division of Infectious Diseases, Department of Medicine, Duke University School of Medicine, \\ Durham, NC USA \\ ${ }^{2} \mathrm{NC}$ Statewide Program for Infection Control and Epidemiology, UNC School of Medicine, Chapel \\ Hill, NC USA \\ ${ }^{3}$ Department of Hospital Epidemiology, University of North Carolina Health System, Chapel Hill, \\ NC USA
}

\begin{abstract}
Background-State-specific healthcare-associated infection (HAI) cost estimates have not been calculated to guide Department of Public Health efforts and investments.

Methods-We completed a cost identification study by conducting a survey of 117 acute care hospitals in NC hospitals to collect surveillance data on patient-days, device-days, and surgical procedures during a one-year. We then calculated expected rates and direct hospital costs of surgical site infections (SSI), C. difficile infection and 3 selected device-related HAIs for hospitals and the entire state using reference datasets such as the National Heatlhcare Safety Network (NHSN).

Results-In total, 67 (53\%) hospitals responded to the survey. The median bed size of respondent hospitals was 140 (IQR 66-350). A "standard" NC hospital diagnoses approximately 100 HAI each year with estimated costs of $\$ 985,000$ to $\$ 2.7$ million. The most common HAI was SSI (73\%). Costs related to SSI accounted for $87 \%$ to $91 \%$ of overall costs. In total, the overall direct annual cost of these five selected HAIs was estimated to be between $\$ 124.1$ and $\$ 347.8$ million in 2009 for the State of NC.
\end{abstract}

Conclusions-Using conservative estimates, HAI led to costs of more than $\$ 100$ million in acute care hospitals in the State of NC in 2009. The majority of costs were due to SSI.

\footnotetext{
(C) 2013 Association for Professionals in Infection Control and Epidemiology, Inc. Published by Mosby, Inc. All rights reserved. Corresponding Author: Deverick J. Anderson, MD, MPH, DUMC Box 102359, Durham, NC 27710, dja@ duke.edu, Fax: (919) 681-7494.

Publisher's Disclaimer: This is a PDF file of an unedited manuscript that has been accepted for publication. As a service to our customers we are providing this early version of the manuscript. The manuscript will undergo copyediting, typesetting, and review of the resulting proof before it is published in its final citable form. Please note that during the production process errors may be discovered which could affect the content, and all legal disclaimers that apply to the journal pertain.
} 


\section{Introduction}

Healthcare-associated infections (HAI) lead to devastating outcomes for patients and substantial costs to the US healthcare system. In total, HAI lead to as many as 99,000 deaths and costs of more than $\$ 30$ billion each year in the US. ${ }^{1,2}$

This enormous burden of morbidity and mortality has caused the public, regulatory agencies and payers to focus on ways to reduce the consequences and costs of these infections. As a result, HAI and, more specifically, hospitals' performances related to prevention of HAI are subject to public reporting requirements in many states. ${ }^{3}$ For example, 29 states are now required to report HAI data to NHSN by law. ${ }^{4}$ Similarly, Centers for Medicare and Medicaid Services (CMS) no longer provides payment for infection due to a central venous catheter and catheter-associated urinary tract infections acquired during hospitalization. ${ }^{5}$ These "pay-for-performance" rules and other financial incentives will likely increase in breadth and scope as private insurers follow suit and as CMS expands the list HAI for which reimbursement is prohibited.

Given these growing concerns about HAI, the US Department of Health and Human Services developed an Action Plan to Prevent Healthcare-Associated Infections (HHS Action Plan) that included specific recommendations for surveillance, research, communication, and metrics for measuring progress towards national goals. ${ }^{6}$ Federal funding became available in 2009 for states to carry out the HHS Action Plan through the American Recovery and Reinvestment Act (P.L. 111-15). ${ }^{7}$ States receiving these funds were required to devise statewide plans for the creation and implementation of interventions designed to prevent HAI and to develop surveillance systems to monitor HAI. To date, however, state-specific HAI cost estimates have not been calculated to guide these efforts.

North Carolina (NC), the 10th most populous state in the US, is home to 9.6 million people and includes metropolitan and rural areas, several prominent industries, universities, and natural areas. ${ }^{8}$ The NC Department of Public Health (DPH) received ARRA funds in 2009 to prevent HAI in acute care hospitals in NC. The DPH in turn formed an HAI Prevention Advisory Panel to determine the methods and identify potential targets for interventions to decrease the incidence of $\mathrm{HAI}$ in NC. A subcommittee was created to determine the cost impact of HAI on the State of NC in order to aid development of a long-term strategy for HAI prevention that included investment by the state legislature. The main goal of this subcommittee was to calculate the direct costs of selected HAI for acute care hospitals in $\mathrm{NC}$ and, subsequently, the state of NC.

\section{Methods}

\section{Survey of North Carolina Hospitals}

A survey was sent to 117 of the 126 acute care hospitals (median bed size 109.5, IQR 50204, including three long term care facilities) in NC in June, 2010. These 117 hospitals were selected because of their prior participation in the NC Statewide Program for Infection Control and Epidemiology (SPICE). Hospitals were asked to provide data for calendar year 2009 for the following variables: licensed bed size, patient-days, ventilator-days, central 
line-days, urinary catheter-days, number of surgical procedures, number of intensive care units (ICU), type of ICU, and number of infection preventionists. In addition, hospitals were requested to provide device-days in their ICU(s) and device days for their entire hospital (including the device days from the ICU(s)). Similarly, hospitals were asked to differentiate between surgical procedures performed in inpatient and outpatient settings. A second survey was sent to non-responders in July, 2010. Survey responses were averaged to determine a "standard" NC acute care hospital. Hospital-specific bed size data for non-responders were obtained from the American Hospital Association. ${ }^{9}$

\section{Estimates for Rates of HAl}

Data published by the National Healthcare Safety Network (NHSN) ${ }^{10}$ were used to determine mean hospital-specific rates for the following infections: central line-associated bloodstream infection (CLABSI), ventilator-associated pneumonia (VAP), catheterassociated urinary tract infection (CA-UTI), and surgical site infection (SSI). NHSN publishes data separately for different types of locations, such as ICU type, non-ICU ward type, and specialty care locations (e.g., 16 distinct ICU types and 20 distinct non-ICU ward types for CLABSI); thus, a weighted-mean rate was calculated for each type of infection based on the number of device days reported to NHSN for each location. Data published by the Duke Infection Control Outreach Network (DICON) were used to determine the average rate of Clostridium difficile infections (CDI) per hospital. ${ }^{11}$

\section{Estimates for Cost of HAls}

Minimum and maximum cost estimates were used for each of the selected HAI, based on published data from the CDC (Table 1). ${ }^{2}$ These estimates represent direct costs for each HAI in 2007 USD based on the Consumer Price Index (CPI) for Inpatient Hospital Services. These estimates were based on three key assumptions: 1) all NC hospitals were assumed to have HAI rates equal to NHSN means; 2) costs were assumed to be equal across all hospitals; 3 ) hospitals were assumed to have the same HAI rate by standardization.

\section{Costs of HAl in North Carolina Hospitals}

Numbers of each of the selected HAI were calculated for the "standard" NC hospital by applying the weighted-mean rates for each of the HAI from NHSN to the medians of the surveillance data from the survey of hospitals. For example, if the "standard" NC hospital accrued 2,000 central line days each year and the weighted-mean rate for CLABSI based on NHSN data was 2.55 CLABSIs/1,000 central line-days, then the "standard" NC hospital would expect to have 5.1 CLABSI each year.

These estimates were then multiplied by the minimum and maximum costs of each specific type of HAI to determine the annual costs for each infection for the "standard" NC hospital. The minimum and maximum costs for each type of infection were summed to determine total minimum and maximum cost estimates of HAI for the "standard" NC hospital. These minimum and maximum cost estimates were then multiplied by 126 (i.e., the number of acute care hospitals in NC) to determine minimum and maximum statewide cost estimates for HAIs for NC. 


\section{Sub- and Sensitivity Analysis}

A sub-analysis was performed to determine costs related to three specific categories of infection: device-related infections in the ICU, SSI following inpatient surgical procedures, and hospital-wide CDI. These categories were selected because published estimates for cost are most specific to these categories. This approach overcomes the limitation of extrapolating costs from a specific area to a broader area. For example, published data from CLABSIs in the ICU may not be accurate for CLABSIs that occur outside the ICU or costs from SSIs diagnosed following inpatient procedures may not be accurate for outpatient surgical procedures.

Two additional sensitivity analyses were performed. First, cost estimates were calculated after limiting the analysis to respondents only. That is, non-respondent hospitals were assumed to have zero HAI; thus, these estimates represent the most conservative estimates possible from our models. Second, we recalculated costs for the State by using hospitalspecific data provided by respondents, instead of calculating costs for a "standard" hospital. This model was created by first applying the weighted-mean rates for each of the HAIs from NHSN to the actual surveillance data from respondents to calculate the estimated number of each specific HAI for each respondent hospital. Total numbers of each of the HAI were then calculated by summing the results for each respondent hospital. These estimates were then multiplied by the minimum and maximum costs of each specific type of HAI to determine the annual costs for each infection for respondent hospitals. After calculating the total number of beds in the 126 acute care hospitals, we calculated the number of beds represented by respondents for each of the HAI (e.g., 62 (49\%) hospitals responded with surgical procedure data, but these 62 hospitals represented $61 \%$ of beds in NC). The minimum and maximum cost estimates for each HAI were then divided by the proportion of beds represented to determine minimum and maximum statewide cost estimates for each HAI (e.g., statewide cost of SSI=total cost at respondent hospitals/0.61). Costs for each HAI were then summed to determine the minimum and maximum statewide cost estimates for the State of NC.

\section{Statistics}

Standard descriptive statistics were used to calculate means, medians, and interquartile ranges (IQR). Medians were compared using the Wilcoxon rank sums test. Statistical testing was performed using SAS v9.2 (Cary, NC).

\section{Results}

In total, 67 (53\%) hospitals responded to the survey. The median bed size of respondent hospitals was 140 (IQR 66-350). Hospitals that responded to the survey were generally larger than non-responding hospitals. The median bed size for hospitals that did not respond was 92 (IQR 43-131; $\mathrm{p}=0.009$ compared to hospitals that responded). The median number of Infection Preventionists (IPs) at each respondent hospital was 1 FTE (IQR 1-2). In general, hospitals were more likely to provide ICU-specific device data than hospital-wide data (Table 2).

Am J Infect Control. Author manuscript; available in PMC 2014 September 01. 
Respondent hospitals in NC were similar to the hospitals that reported to NHSN based on bed size. For example, hospitals in NC that responded to the survey and hospitals that report to NHSN had the same proportion of hospitals with bed size less than 200 (63\% of NC hospitals vs. $64 \%$ of NHSN hospitals).

The "standard" NC hospital detects approximately 100 HAIs each year (Table 3). The most common HAI was SSI (73\% of HAIs). Overall, the cost of the selected HAI in the “standard" NC hospital was between $\$ 985,000$ and $\$ 2.7$ million annually (Table 3). Costs related to SSI accounted for $87 \%-91 \%$ of overall costs. After restricting the calculation to costs in the ICUs for device-related infections, SSIs following inpatient surgical procedures, and hospital-wide CDI, the cost of HAI in the "standard" NC hospital was between $\$ 436,000$ and $\$ 1.1$ million annually.

These estimates for direct costs due to HAI for the "standard" NC hospital were then applied to all 126 acute care hospitals in NC. In total, the overall direct annual cost of these five selected HAI for the State of NC was estimated to be between \$124.1 and \$347.8 million. When our calculations were restricted to costs in the ICU for device-related infections, SSIs following inpatient surgical procedures, and hospital-wide CDI, the total overall direct annual cost of these five selected HAI for the state of North Carolina was estimated to be between \$54.9 and \$144.3 million (Table 4).

Finally, two additional sensitivity analyses were performed. First, after limiting costs to only respondent hospitals, the overall direct annual cost of these five selected HAI for the State of $\mathrm{NC}$ was estimated to be between $\$ 66.0$ and $\$ 184.9$ million. Second, we tested the assumption that calculating rates and costs for a "standard" $\mathrm{NC}$ hospital was an appropriate approach by creating a model that relied only on surveillance data provided by respondents. Using this approach, the overall direct annual cost of the five selected HAI for the State of $\mathrm{NC}$ was estimated to be between $\$ 224$ and $\$ 617.7$ million.

\section{Discussion}

Our study is the first to provide statewide estimates for the direct costs of HAI. Using estimates published by the CDC and surveillance data, we conservatively estimate that HAI cost the State of NC greater than $\$ 100$ million each year. These estimates may help Departments of Public Health in other states and other advocates of infection prevention determine and validate potential investments in HAI prevention in their state or region. Finally, our methods can potentially be reproduced for other states to calculate their statespecific HAI costs.

Of note, SSI led to the highest overall cost, accounting for approximately $90 \%$ of the costs of HAIs in the state of NC. Thus, our analysis suggests that initiatives to reduce the costs of HAI should focus primarily on preventing SSIs. Assuring knowledge of and compliance with national guidelines for the prevention of SSI would be a first step, ${ }^{12}$ but novel interventions are needed as well.

Our cost estimates for HAI have wide ranges, reflecting the difficulties in studying and publishing data on cost of HAI. Regardless of the actual amount or range, all studies that we 
are familiar with have demonstrated that HAI are expensive. In addition to lost-opportunity costs for hospitals, HAI lead to costs to society including early deaths and disability. ${ }^{1,13-15}$ Thus, our data provide further incentives for all hospitals and states to invest in HAI prevention programs. This incentive is particularly relevant because most hospitals have progressively received less reimbursement for patients with several types of HAI. Indeed this trend in declining reimbursement is likely to continue or accelerate as federal agencies and payers seek new ways to promote quality of care and to reduce costs. For example, CMS will soon initiate programs that promote "value-based purchasing programs" in which hospitals with higher rates of HAI will receive less support from CMS than hospitals with low rates. These programs will reduce margins even further for many hospitals. ${ }^{16}$

Our estimates likely underestimate the true cost of HAI in the state of NC for several reasons. First, respondent hospitals were generally larger than non-responding hospitals. Rates of some HAI and adverse outcomes such as SSI and VAP are higher in smaller community hospitals than medium-sized community hospitals; ${ }^{17-19}$ thus, our rate estimates and subsequently our cost estimates may be low, particularly since the majority of infections and cost were due to SSI. Second, these estimates were calculated using previously published estimates of direct costs of HAI and do not include indirect costs and subsequent costs to society from lost wage and production. ${ }^{20}$ Third, these estimates only include 5 types of HAIs. These HAIs constitute only $50 \%$ of HAIs $;{ }^{21}$ costs of other HAI (e.g., hospitalacquired pneumonia in the absence of the ventilator) were not included. Fourth, the differential increase in costs due to HAI caused by multidrug-resistant pathogens was not included. Finally, our sensitivity analysis using actual surveillance data instead of extrapolating from a "standard" NC hospital led to higher cost estimates.

Though likely underestimations, our estimates and cost models need to be interpreted with caution. In fact, our goal was not necessarily to calculate a specific value for the overall cost of HAI but, instead, to create general estimates to help guide policy decisions and potential investment. HAI outcome data (as reported to the NHSN and as obtained by hospitals across the US) likely suffers from "surveillance bias". 22,23 Thus, surveillance data likely underestimate of true number of HAI occurring in hospitals in NC. In addition, cost considerations depend a great deal on perspective, including hospital (lost opportunity), patient (outcomes), and society (lost wage and production). Finally, not all HAI are preventable. In fact, a recent report by Umscheid et al. stated that as many as one-third of all cases of CLABSI and CAUTI and almost half of all cases of VAP and SSI were not preventable. ${ }^{24}$ Thus, our estimates do not represent the total amount of money that could potentially be saved through enhanced infection prevention.

Our study has other limitations. First, the biggest limitation of our study is the 53\% response rate. Thus, our estimates may not accurately represent infection rates at non-responders. On the other hand, we believe that the size difference between respondent and non-responding hospitals would lead to an under-estimation of rates and costs, as described above. Second, the cost estimates published by the CDC may suffer from the same limitations of the studies used to create the estimates. More specifically, these studies may have had suboptimal or incomplete matching. ${ }^{25}$ In addition, propensity scores were not used to match cases and controls. ${ }^{26}$ Finally, our estimates were not adjusted for inflation. 
In summary, our study provides an estimate of the total cost of HAI for the State of NC each year. To our knowledge, no other groups have utilized state surveillance estimates to estimate state costs. The cost of HAI to hospitals in NC is staggeringly high, and SSI costs account for the large majority of these costs. Our efforts to estimate the costs of HAI in a single state should be viewed as a small but necessary step in helping other states define the nature of the problems facing their individual hospitals. Our estimates can also be used to formulate and justify the next critical steps for improving the care of hospitalized patients: designing, promoting and maintaining new and better programs that actually prevent HAI. Indeed it is necessary to define and understand the economic costs of HAI before mobilizing the resources and incentives to reduce the incidence of infections that generate these costs. Finally, costs can in turn be one of several outcomes that is used to measure the effectiveness of prevention efforts and to justify their costs.

\section{References}

1. Klevens RM, Edwards JR, Richards CL Jr, et al. Estimating health care-associated infections and deaths in U.S. hospitals, 2002. Public Health Rep. Mar-Apr;2007 122(2):160-166. [PubMed: 17357358]

2. Scott, RD. The direct medical costs of healthcare-associated Infections in US hospitals and the benefits of prevention. Atlanta, GA: Division of Healthcare Quality Promotion National Center for Preparedness, Detection, and Control of Infectious Diseases Coordinating Center for Infectious Diseases Centers for Disease Control and Prevention; 2009.

3. [Accessed May 1, 2012.] Hospital Compare. 2012. http://hospitalcompare.hhs.gov/

4. [Accessed May 1, 2012.] State Based HAI Prevention. 2012. http://www.cdc.gov/hai/stateplans/ required-to-report-hai-NHSN.html

5. Centers for M, Medicaid Services HHS. Medicare program; changes to the hospital inpatient prospective payment systems and fiscal year 2008 rates. Federal Register. Aug 22; 2007 72(162): 47129-48175. [PubMed: 17847578]

6. National Action Plan to Prevent Healthcare-Associated Infections: Roadmap to Elimination. [Accessed May 1, 2012.] US Department of Health and Human Services. 2012. http:// www.hhs.gov/ash/initiatives/hai/actionplan

7. [Accessed May 1, 2012.] American Recovery and Reinvestment Act of 2009. 2009. http:// thomas.loc.gov/cgibin/toGPObsspubliclaws/http://www.gpo.gov/fdsys/pkg/PLAW-111publ5/pdf/ PLAW-111pub15.pdf. Page 180

8. [Accessed May 1, 2012.] State \& County QuickFacts - North Carolina. 2012. (http:// quickfacts.census.gov/qfd/states/37000.html

9. [Accessed July 17, 2007.] Fast Facts on US Hospitals. 2007. http://www.aha.org/aha/resourcecenter/Statistics-and-Studies/fast-facts.html

10. Edwards JR, Peterson KD, Mu Y, et al. National Healthcare Safety Network (NHSN) report: data summary for 2006 through 2008, issued December 2009. Am J Infect Control. Dec; 2009 37(10): 783-805. [PubMed: 20004811]

11. Miller BA, Chen LF, Sexton DJ, Anderson DJ. Comparison of the burdens of hospital-onset, healthcare facility-associated Clostridium difficile Infection and of healthcare-associated infection due to methicillin-resistant Staphylococcus aureus in community hospitals. Infect Control Hosp Epidemiol. Apr; 2011 32(4):387-390. [PubMed: 21460491]

12. Anderson DJ, Kaye KS, Classen D, et al. Strategies to prevent surgical site infections in acute care hospitals. Infect Control Hosp Epidemiol. Oct; 200829 (Suppl 1):S51-61. [PubMed: 18840089]

13. Cosgrove SE, Qi Y, Kaye KS, Harbarth S, Karchmer AW, Carmeli Y. The impact of methicillin resistance in Staphylococcus aureus bacteremia on patient outcomes: mortality, length of stay, and hospital charges. Infect Control Hosp Epidemiol. Feb; 2005 26(2):166-174. [PubMed: 15756888] 
14. Jarvis WR. Selected aspects of the socioeconomic impact of nosocomial infections: morbidity, mortality, cost, and prevention. Infect Control Hosp Epidemiol. Aug; 1996 17(8):552-557. [PubMed: 8875302]

15. Kirkland KB, Briggs JP, Trivette SL, Wilkinson WE, Sexton DJ. The impact of surgical-site infections in the 1990s: attributable mortality, excess length of hospitalization, and extra costs. Infect Control Hosp Epidemiol. Nov; 1999 20(11):725-730. [PubMed: 10580621]

16. Thompson CA. CMS reveals Medicare's value-based purchasing program for hospitals. Am J Health Syst Pharm. Jun 15; 2011 68(12):1062-1071. [PubMed: 21642559]

17. Anderson DJ, Hartwig MG, Pappas T, et al. Surgical Volume and the Risk of Surgical Site Infection in Community Hospitals: Size Matters. Ann Surg. Feb; 2008 247(2):343-349. [PubMed: 18216543]

18. Kahn JM, Goss CH, Heagerty PJ, Kramer AA, O’Brien CR, Rubenfeld GD. Hospital volume and the outcomes of mechanical ventilation. The New England journal of medicine. Jul 6; 2006 355(1):41-50. [PubMed: 16822995]

19. Lee, MS.; Walker, V.; Chen, LF.; Sexton, DJ.; Anderson, DJ. ID Week 2012 Abstract \#1104. San Diego, CA, USA: 2012. The Epidemiology of Ventilator Associated Pneumonia (VAP) in a Network of Community Hospitals: A Prospective, Multicenter Study.

20. Anderson DJ, Kirkland KB, Kaye KS, et al. Underresourced hospital infection control and prevention programs: penny wise, pound foolish? Infect Control Hosp Epidemiol. Jul; 2007 28(7): 767-773. [PubMed: 17564977]

21. Weber DJ, Sickbert-Bennett EE, Brown V, Rutala WA. Completeness of surveillance data reported by the National Healthcare Safety Network: an analysis of healthcare-associated infections ascertained in a tertiary care hospital, 2010. Infect Control Hosp Epidemiol. Jan; 2012 33(1):9496. [PubMed: 22173531]

22. Haut ER, Pronovost PJ. Surveillance bias in outcomes reporting. Jama. Jun 15; 2011 305(23): 2462-2463. [PubMed: 21673300]

23. Lin MY, Bonten MJ. The dilemma of assessment bias in infection control research. Clin Infect Dis. May; 2012 54(9):1342-1347. [PubMed: 22337824]

24. Umscheid CA, Mitchell MD, Doshi JA, Agarwal R, Williams K, Brennan PJ. Estimating the proportion of healthcare-associated infections that are reasonably preventable and the related mortality and costs. Infect Control Hosp Epidemiol. Feb; 2011 32(2):101-114. [PubMed: 21460463]

25. Wakefield DS, Pfaller MA, Hammons GT, Massanari RM. Use of the appropriateness evaluation protocol for estimating the incremental costs associated with nosocomial infections. Med Care. Jun; 1987 25(6):481-488. [PubMed: 3695657]

26. Ben-David D, Novikov I, Mermel LA. Are there differences in hospital cost between patients with nosocomial methicillin-resistant Staphylococcus aureus bloodstream infection and those with methicillin-susceptible S aureus bloodstream infection? Infect Control Hosp Epidemiol. May; 2009 30(5):453-460. [PubMed: 19344266] 
Table 1

Direct Cost Estimates for Selected HAIs in 2007 USD [3]

\begin{tabular}{|lcc|}
\hline Type of Infection & Minimum Cost & Maximum Cost \\
\hline Central line-associated bloodstream infection & $\$ 7,288$ & $\$ 29,156$ \\
Ventilator-associated pneumonia & $\$ 19,633$ & $\$ 28,508$ \\
Catheter-associated urinary tract infection & $\$ 862$ & $\$ 1,007$ \\
Surgical site infection & $\$ 11,874$ & $\$ 34,670$ \\
Clostridium difficile infection & $\$ 6,408$ & $\$ 9,124$ \\
\hline
\end{tabular}


Table 2

Summary of surveillance data from acute care hospitals in North Carolina

\begin{tabular}{|lccc|}
\hline Variable & Number of Respondents N $(\%)$ & Median & IQR \\
\hline Patient-days & $66(99)$ & 24980.5 & $(10047-52972)$ \\
Central line-days & & & \\
$\quad$ ICU & $56(84)$ & 1031.5 & $(256.6-2837.5)$ \\
$\quad$ Hospital-wide & $39(58)$ & 1952 & $(366-6738)$ \\
Ventilator-days & & & \\
$\quad$ ICU & $58(87)$ & 709 & $(184-2051)$ \\
$\quad$ Hospital-wide & $59(88)$ & 646 & $(168-2051)$ \\
Urinary catheter-days & & & \\
$\quad$ ICU & $49(73)$ & 2011 & $(949-3925)$ \\
$\quad$ Hospital-wide & $34(51)$ & 2895 & $(1239-9839)$ \\
Surgical procedures (total) & $62(93)$ & 3752 & $(2113-9637)$ \\
$\quad$ Inpatient & $45(67)$ & 1380 & $(400-3938)$ \\
$\quad$ Outpatient & $47(70)$ & 3931 & $(1378-6557)$ \\
\hline
\end{tabular}

ICU - Intensive care unit; IQR - interquartile range 


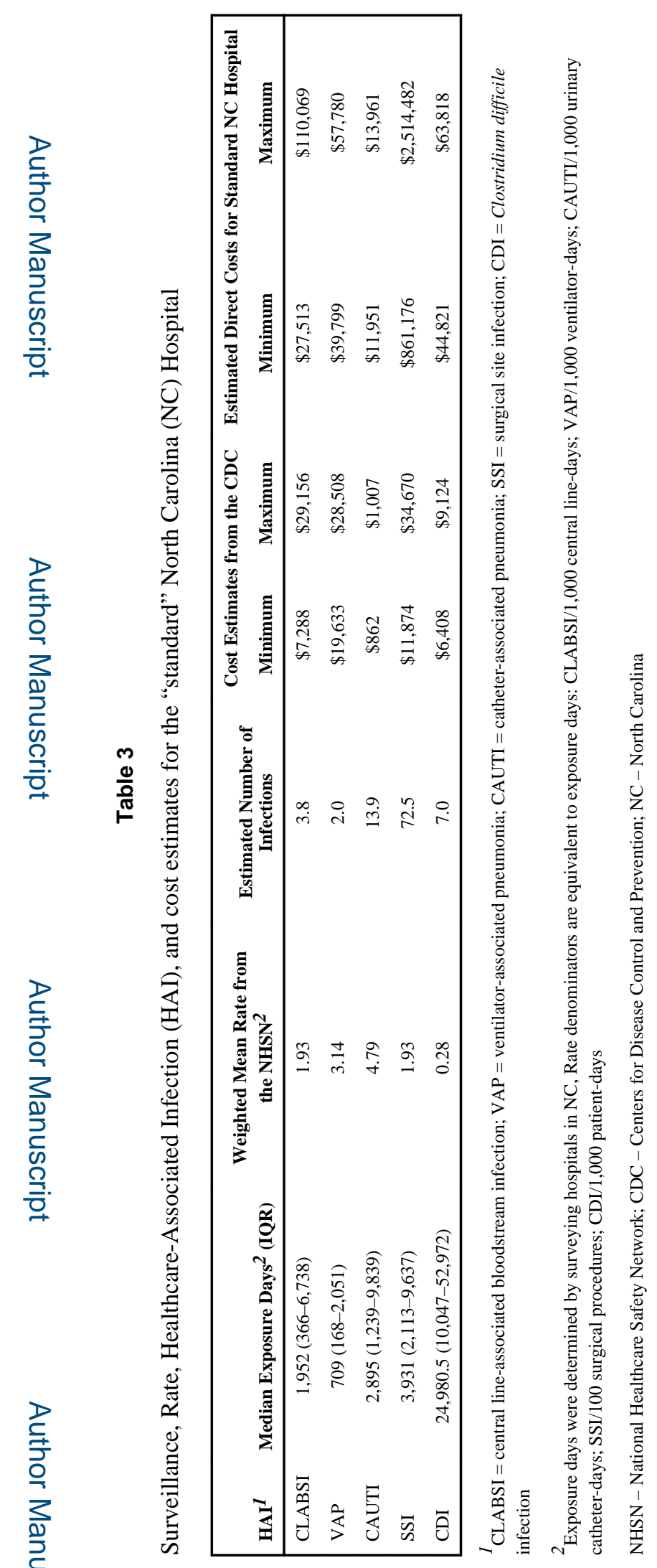

Am J Infect Control. Author manuscript; available in PMC 2014 September 01. 


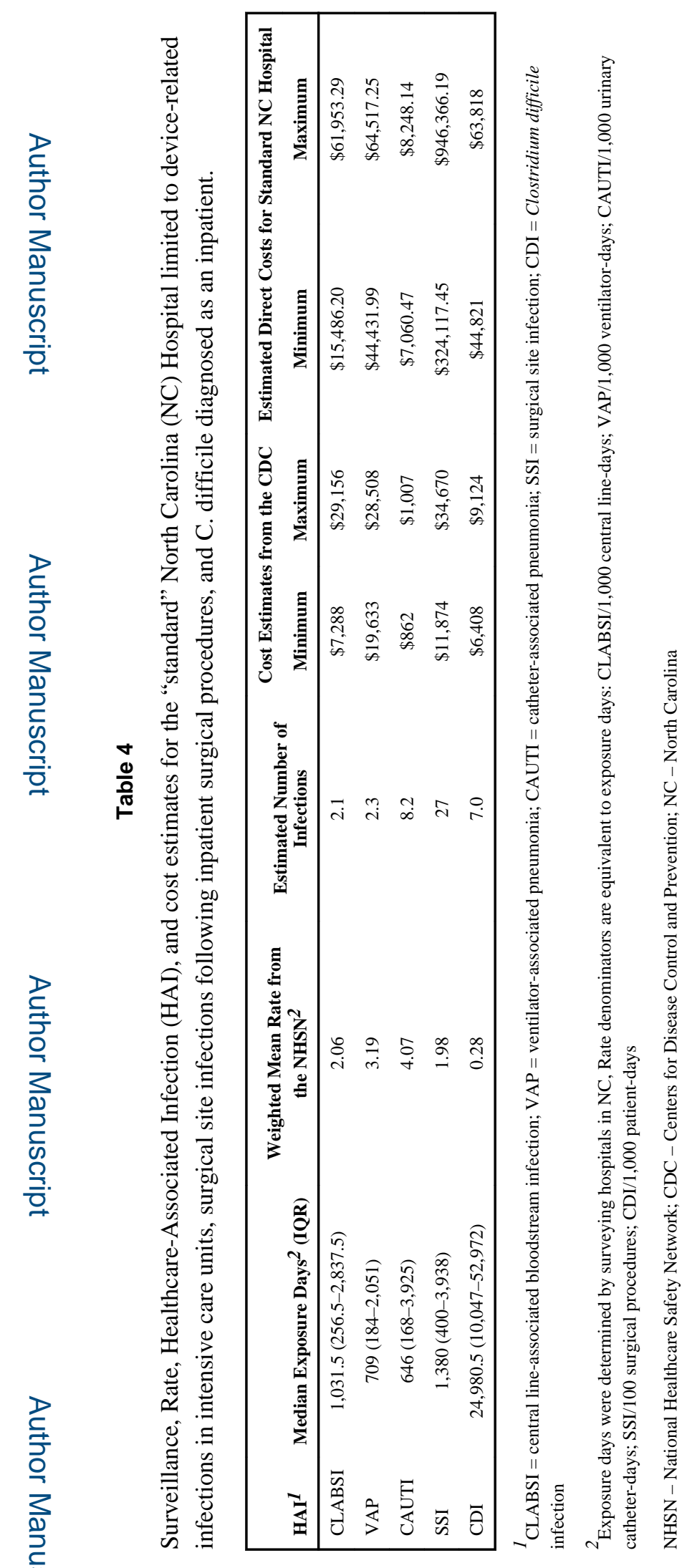

Am J Infect Control. Author manuscript; available in PMC 2014 September 01. 